\title{
Clinical effect of photodynamic therapy on primary carious dentin after partial caries removal
}

\section{Pierre Adriano Moreno NEVES(a) Leonardo Abrantes LIMA(a) Fernanda Cristina Nogueira RODRIGUES(b) \\ Tarcisio Jorge LEITÃO(c) \\ Cecília Cláudia Costa RIBEIRO(c)}

(a) Universidade Federal do Maranhão UFMA, School of Dentistry, Postgraduate Program in Dentistry, São Luís, MA, Brazil.

(b) Universidade Federal do Maranhão - UFMA, School of Dentistry, São Luís, MA, Brazil.

(c) Universidade Federal do Maranhão UFMA, School of Dentistry, Department of Dentistry II, São Luís, MA, Brazil.

Declaration of Interests: The authors certify that they have no commercial or associative interest that represents a conflict of interest in connection with the manuscript.

\section{Corresponding Author:}

Cecília Cláudia Costa Ribeiro

E-mail: cecília_ribeiro@hotmail.com

DOI: 10.1590/1807-3107BOR-2016.vol30.0047

Submitted: May 30, 2015

Accepted for publication: Jan 20, 2016

Last revision: Feb 19, 2016
Abstract: This study was conducted to assess the clinical effect of photodynamic therapy (PDT) in the decontamination of the deep dentin of deciduous molars submitted to partial removal of carious tissue. After cavity preparation, dentin samples were taken from the pulp wall of nineteen deciduous molars before and after PDT application. Remaining dentin was treated with $0.01 \%$ methylene blue dye followed by irradiation with an InGaAlP diode laser $\left(\lambda-660 \mathrm{~nm} ; 40 \mathrm{~mW} ; 120 \mathrm{~J} / \mathrm{cm}^{2} ; 120 \mathrm{~s}\right)$. Dentin samples were microbiologically assessed for the enumeration of total microorganisms, Lactobacillus spp. and mutans streptococci. There was no significant difference in the number of colony-forming units (CFU) for any of the microorganisms assessed ( $p>0.05$ ). Photodynamic therapy, using $0.01 \%$ methylene blue dye at a dosimetry of $120 \mathrm{~J} / \mathrm{cm}^{2}$ would not be a viable clinical alternative to reduce bacterial contamination in deep dentin.

Keywords: Lasers; Photochemotherapy; Tooth, Deciduous.

\section{Introduction}

The innerportion part of the carious dentin, deep dentin, is a vital tissue with a robust collagen structure that is capable of remineralization. ${ }^{1}$ Less invasive restoration techniques have been used to maintain this dentin layer. It has been shown that, after cavity restoration, there is a drastic reduction in both the genotypic and phenotypic complexity of the microbiota. ${ }^{2,3}$

However, some studies show that microorganisms, including Streptococcus mutans, may adapt to this new environment created under the restorations after the incomplete removal of the carious dentin. ${ }^{4}$

Bacteria may persist in the dentin after cavity preparation, even after "complete" removal of carious tissue, ${ }^{3}$ which is driving the search for alternative treatments aimed at reducing the number of microorganisms after interventions for removing carious tissue. ${ }^{5}$

Photodynamic Therapy (PDT) is currently being studied as an antimicrobial alternative with an effect on the microorganisms involved in caries. ${ }^{6}$ This technique is based on the application of a light source to activate a photosensitizer (PS), which in the presence of oxygen, produces singlet oxygen and free radicals that irreversibly damage cellular components and modify metabolic activities, leading to cell death. ${ }^{7}$

The antimicrobial effectiveness of PDT has been demonstrated under laboratory conditions on planktonic cultures, ${ }^{8}$ monospecies biofilms of certain genera of streptococcus, including Streptococcus 
mutans ${ }^{9}$ and also in multi-species biofilms. ${ }^{10}$ PDT's $^{\prime}$ effects on carious dentin formed under experimental conditions through in vitro ${ }^{11}$ and in situ $u^{12}$ models has also been shown.

However, the response to PDT inside the oral cavity may be different from the results so far under experimental conditions. ${ }^{7}$ In fact, a study has shown that, using the same dosimetry, PDT reduced microbial levels in the in vitro biofilm and had little effect on microbial levels in the in situ situation. ${ }^{13}$

We have found only one in vivo study that assessed the effect of PDT/ Methylene blue on contaminated dentin of permanent teeth, which showed a reduction in the number of viable bacteria (total microorganisms, mutans streptococci, Lactobacillus spp.) on the order of one decimal reduction after applying a low-power laser. ${ }^{14}$ Therefore, further studies into the effectiveness of PDT in clinical situations are required, including analysis of its effects on the remaining pulp wall. Thus, the goal of this study was to evaluate the clinical effect of using photodynamic therapy (PDT) to decontaminate the deep dentin of primary molars submitted to partial removal of carious tissue.

\section{Methodology}

\section{Sample selection}

The study was approved by the Research Ethics Committee of the Universidade Federal do Maranhão - UFMA under no. 23115-004903/2011-24. Parents or legal guardians received detailed information about the study and signed a free and informed consent form to permit the children to participate in the study. All children received full dental care in the Pediatric Dentistry Clinic of the UFMA.

The sample size used in this study was based on a previous study of our group regarding the partial removal of carious dentin; there, it was determined that sixteen teeth were required to obtain a test power of $80 \%$ at a significance level of $5 \%$ and with a maximum error of the estimate of 0.6 colony-forming units. ${ }^{3}$

To select the samples, 418 children aged between 6 and 10 years from five public schools in the municipality of São Luís (state of Maranhão, Brazil) were examined. Children with systemic diseases or who had used antibiotics in the three months preceding the study were excluded, as these factors might interfere in the etiological factors of the disease.

The inclusion criteria were children with deciduous teeth with active carious cavities scoring 6 (Extensive distinct cavity with visible dentin) in the ICDAS index (International Caries Detection and Assessment System $){ }^{15}$ plus inner half of the dentin confirmed by radiological examination. Teeth showing clinical or radiographic signs of irreversible damage to the pulp such as spontaneous pain, fistula or radiographic alteration in the interradicular or periapical region were excluded. ${ }^{3}$ Thirty-four children were selected to participate in the study, but only 19 arrived at the appointed date for the experiment (Figure 1).

\section{Cavity preparation}

The teeth of the patients were anesthetized and isolated using a rubber dam. Next, a high-speed bur no. 1011 (KG Sorensen, São Paulo, Brazil) was used to gain access to the caries lesion. Cavity preparation was limited to the total removal of carious tissue from the cavosurface angle and surrounding walls. The infected dentin was superficially removed from the pulp wall using low-speed sterile no. 3 carbide (KG Sorensen, São Paulo, Brazil) bur. ${ }^{3}$ Calibration of the examiner for partial caries removal was performed on 20 extracted deciduous molars which were evaluated after treatment by a second examiner experienced in this procedure (C.C.C.R.). A kappa value of 0.85 was obtained.

After cavity preparation, a first sample of dentin was collected from the remnant pulp wall using another low-speed sterile no. 3 carbide (KG Sorensen, São Paulo, Brazil) bur (samples before PDT) to assess the microbiological state of this tissue. ${ }^{16}$ After sampling, the bur was transferred to an Eppendorf tube containing glass beads and $1 \mathrm{~mL} 0.9 \%$ saline $(\mathrm{NaCl} 0.9 \%)$ and kept on ice for microbiological processing within one hour (Figure 2).

\section{Application of PDT and restorative procedure}

After collecting the first sample of dentin, the photosensitizing dye methylene blue at $0.01 \%$ (Aptivalux, Belo Horizonte, Brazil) was applied to the whole cavity for 5 minutes. This pre-irradiation step was the 


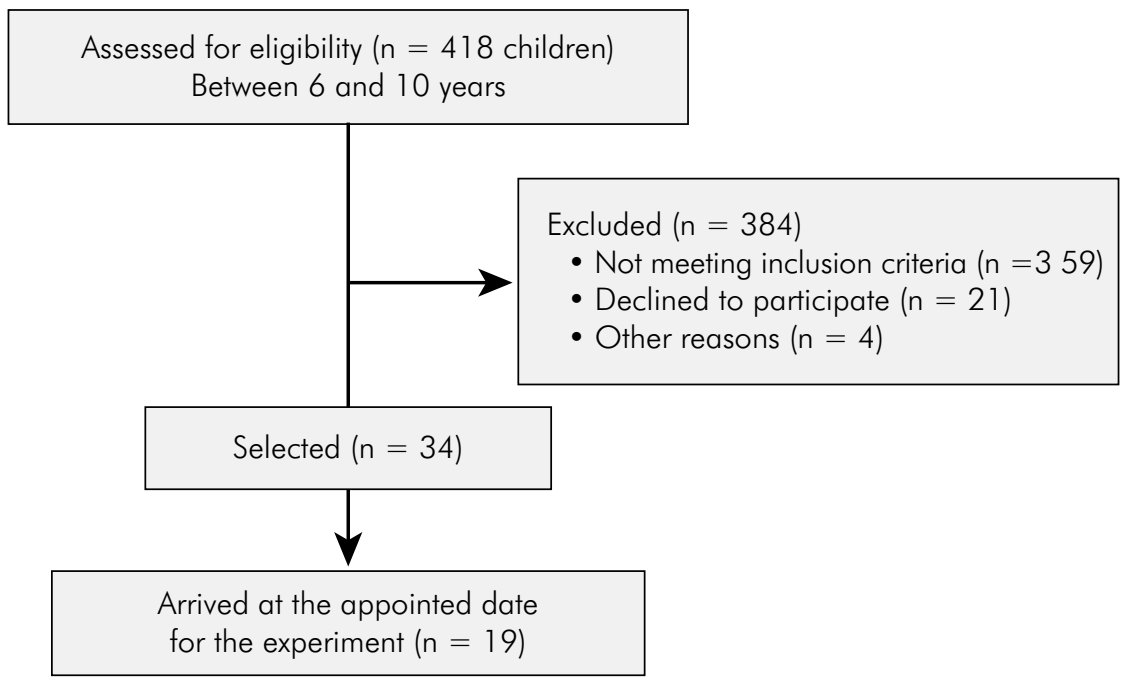

Figure 1. Flow chart subject enrollment.

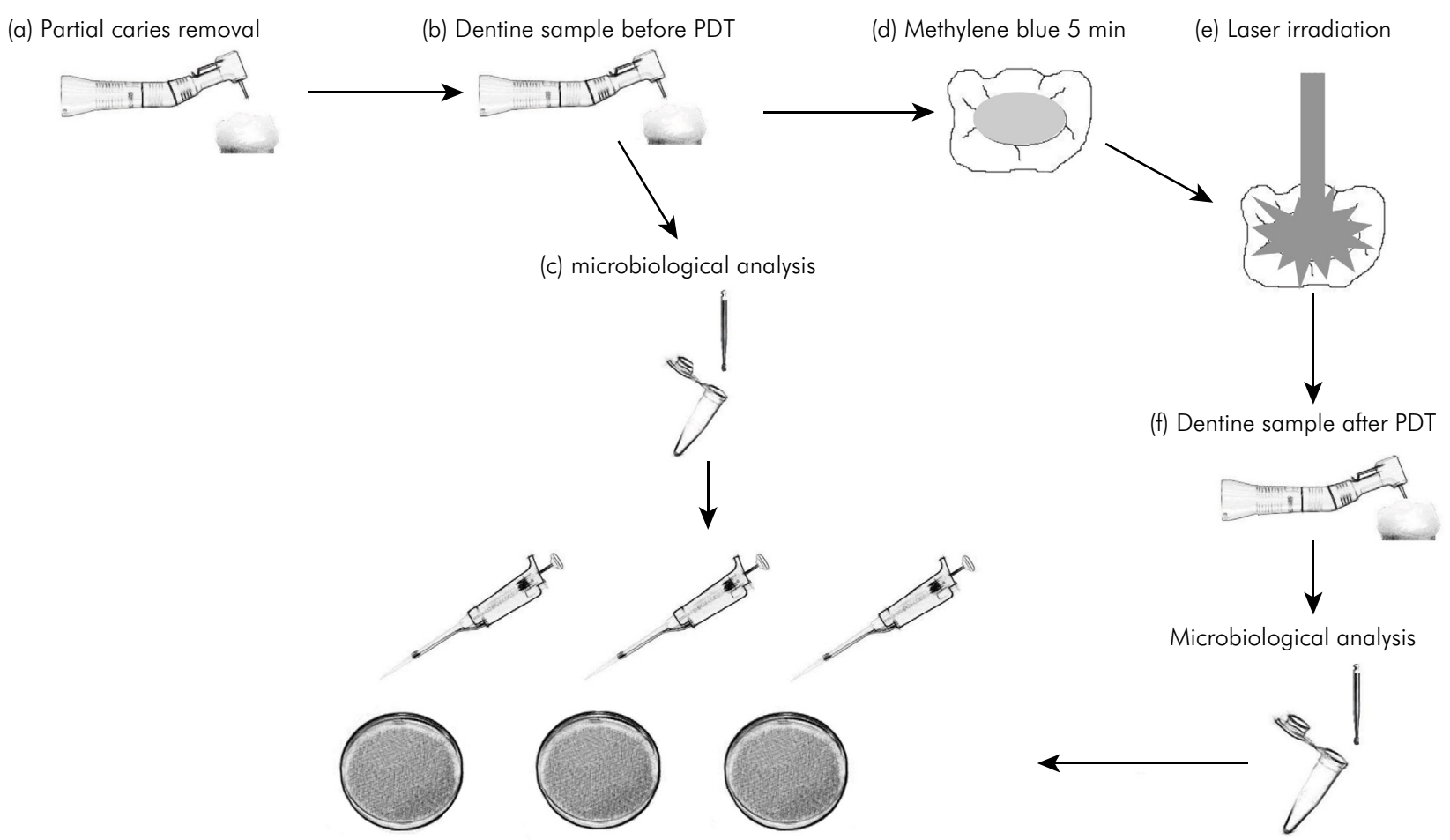

Total microorganisms Mutans streptococci Lactobacillus spp.

Figure 2. Experimental design of the study.

same used in permanent molars where PDT reduced microbial levels of caries related microorganims. ${ }^{14}$

The complex microbiota of the active caries lesion was the reason methylene blue was selected for this experiment. In vitro study have shown that methylene blue is a cationic photosensitizer that can inactivate both gram-positive and gram-negative bacteria after applying PDT with a low-power red laser. ${ }^{17}$

After the 5 min with methylene blue were elapsed, every tooth was irradiated with a low power diode 
laser (InGaAlP - Indium Gallium Aluminum Phosphide) with dosimetry of $120 \mathrm{~J} / \mathrm{cm}^{2}$, power density of $1 \mathrm{~W} / \mathrm{cm}^{2}$ for $120 \mathrm{~s}$, receiving energy of $4,8 \mathrm{~J}$. The device parameters were: output power of $40 \mathrm{~mW}, 660 \mathrm{~nm}$ wavelength and spot size of $0.04 \mathrm{~cm}^{2}$. The active tip of the laser was placed perpendicular to the cavity, as close as possible to the stained dentin (average $0.25 \mathrm{~cm}$ from cavity floor), being cavity's opening the tip approximation limit. Next, a new dentin sample (sample after PDT) was collected at a site adjacent to that of the first sample for microbiological processing (Figure 2).

All teeth were protected with calcium hydroxide cement (Dentsply, Milford, USA), etched with 37\% phosphoric acid for $15 \mathrm{~s}$, and restored with an adhesive and resin composite system (3M ESPE, Minneapolis, USA) according to manufacturer instructions.

\section{Microbiological analysis}

To estimate the number of microorganisms present in $1 \mathrm{mg}$ dentin (CFU/mg), dentin weight was calculated from the difference between the whole set - tube, glass beads, saline and bur with dentin and the previously assessed weight of the set without the dentin sample. ${ }^{3}$

After weighing, the tubes were shaken in a vortex for $30 \mathrm{~s}$ to disperse the sample. ${ }^{3} \mathrm{~A} 100 \mu \mathrm{L}$ aliquot of the dispersed suspension was used to prepare serial dilutions (1:10, 1:100, 1:1.000, 1:10.000 e 1:100.000). Twenty microliter aliquots of each dilution were incubated in duplicate in the following media: blood agar for total microorganism count; mitis salivarius agar supplemented with 0.2 units/mL bacitracin and $15 \%$ sucrose for mutans streptoccci count ${ }^{18}$ and Rogosa agar (RG), for Lactobacillus spp count. ${ }^{19}$ The Rogosa and blood agar plates were incubated under anaerobic conditions for $48 \mathrm{~h},^{20}$ whereas the MSB plates were incubated in an atmosphere of $5 \% \mathrm{CO}_{2}$ for the same period of time. ${ }^{18}$

After incubation, the CFU number was counted in dilutions containing 6-60 colonies. Microbial counts were conducted using a stereo microscope (Quimis ${ }^{\circledR}$, São Paulo, Brazil) by a single examiner who was blinded to the previous clinical procedure. The reproducibility of the counting method was assessed by comparing the microorganism counts for each sample's duplicate plates: the counts were positively correlated $(r=0.92 ; p<0.001)$.

\section{Statistical analysis}

The experimental unit used as a parameter for analysis was the tooth, and CFU counts before and after PDT were compared in each culture medium: blood agar, MSB agar and Rogosa agar. The data distribution was found to be non-normal using the Shapiro-Wilk test. The Box-Cox method was used to $\log 10$-transform the data. After this transformation, CFU counts were analyzed using the Wilcoxon test. The BioEstat 5.3 software (Instituto Mamirauá, Belém, Brazil) was used in these analyses, and a level of significance of $5 \%$ was adopted.

\section{Results}

The results of this study showed no statistically significant difference in the viable microorganisms count before and after application of PDT in molars submitted to partial removal of carious tissue. The therapy promoted an average log-reduction of 0.61 in total microorganisms, 0.44 in mutans streptococci and 0.46 in Lactobacillus spp. (Figure $3 \mathrm{a}, 3 \mathrm{~b}$ and $3 c)$; however, this reduction was not significant $(\mathrm{p}>0.05)$ (Table).

Table. CFU count (means \pm standard deviation) before and after photodynamic therapy with a $120 \mathrm{~J} / \mathrm{cm}^{2} \mathrm{dose}$.

\begin{tabular}{|c|c|c|c|c|c|c|c|}
\hline \multirow{2}{*}{ Dose } & & \multicolumn{2}{|c|}{ Total microorganisms } & \multicolumn{2}{|c|}{ Mutans streptococci } & \multicolumn{2}{|c|}{ Lactobacillus spp. } \\
\hline & & before & after & before & after & before & after \\
\hline \multirow{3}{*}{$120 \mathrm{~J} / \mathrm{cm}^{2}$} & CFU $\left(\log _{10}\right)$ & $3.93 \pm 0.93$ & $3.32 \pm 1.68$ & $2.17 \pm 1.85$ & $1.73 \pm 1.77$ & $1.51 \pm 1.97$ & $1.05 \pm 1.67$ \\
\hline & Variation (\%) & \multicolumn{2}{|c|}{$14.71 \pm 41.03$} & \multicolumn{2}{|c|}{$34.5 \pm 49.19$} & \multicolumn{2}{|c|}{$20.25 \pm 43.71$} \\
\hline & $\mathrm{p}$ & \multicolumn{2}{|c|}{0.3981} & \multicolumn{2}{|c|}{0.4265} & \multicolumn{2}{|c|}{0.4990} \\
\hline
\end{tabular}

CFU: colony-forming unit. 

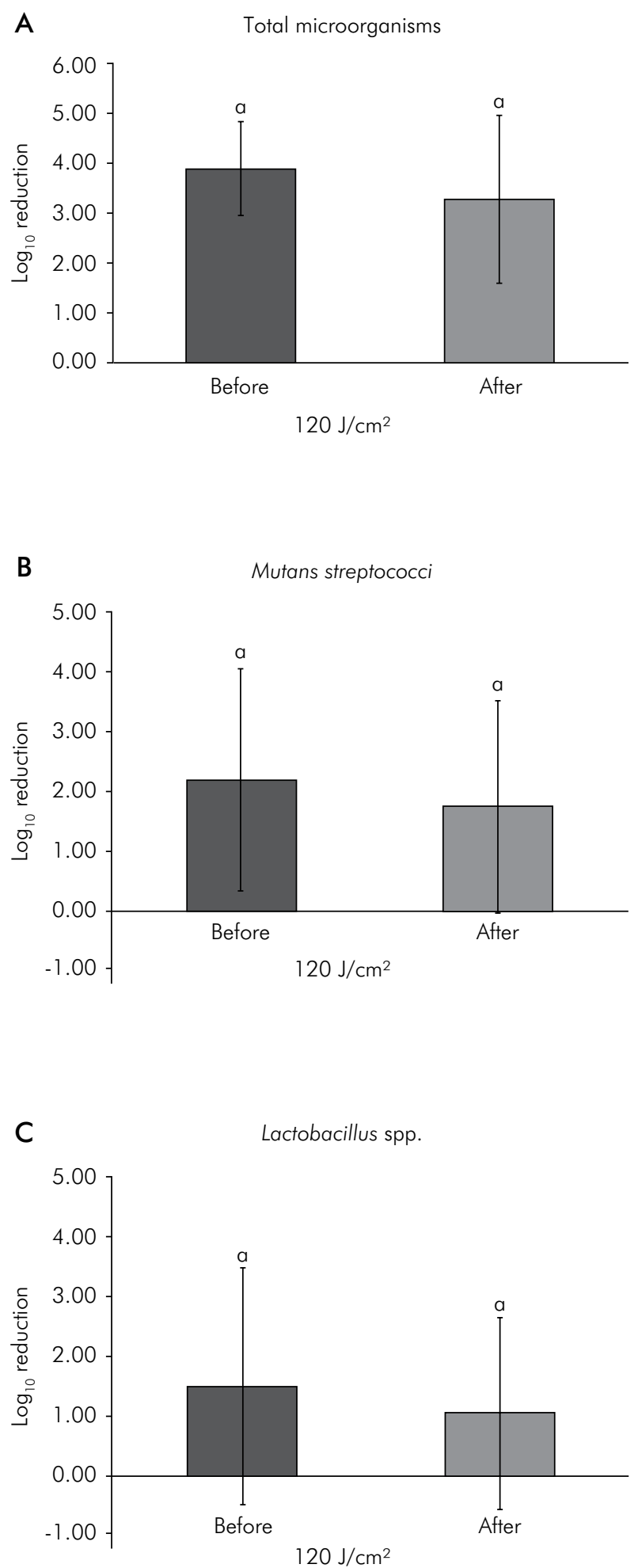

Figure 3. a) Effect of PDT with $120 \mathrm{~J} / \mathrm{cm}^{2}$ dose on the total microorganism count; b) Effect of PDT with $120 \mathrm{~J} / \mathrm{cm}^{2}$ dose on the Mutans streptococci count; c) Effect of PDT with $120 \mathrm{~J} / \mathrm{cm}^{2}$ dose on the Lactobacillus spp. count. The data represent the Log reduction, and the error bars represent the standard deviation. Data followed by same letters represent no significant difference $(p>0.05)$.

\section{Discussion}

In this study, PDT was not effective at reducing contamination in the deep dentin of deciduous teeth using a dosimetry of $120 \mathrm{~J} / \mathrm{cm}^{2}$.

The susceptibility of the microorganisms involved in caries disease grown in planktonic culture to PDT, using lower energy levels than in this study, namely between 24 and $72 \mathrm{~J} / \mathrm{cm}^{2}$, has already been reported in the literature. ${ }^{13,21}$ Additionally, the effect of PDT on microbial reduction has also been shown in experimental models of carious dentin based on induced caries lesions in bovine dentin ${ }^{11}$ and the "in situ" caries model on human dentin, ${ }^{12}$ even with intensities below the ones used in this experiment, i.e., between 24 and $94 \mathrm{~J} / \mathrm{cm}^{2}$, respectively.

Differences in experimental conditions may explain the discrepancies between this clinical study and studies under controlled conditions. Previous in vitro studies used planktonic cells with reduced antimicrobial resistance, ${ }^{21}$ whereas the studies that induced the formation of in vitro and in situ biofilms displayed less microbiological complexity than deep caries cavities. ${ }^{22,23}$ For these reasons, the response to PDT in the oral cavity may be different from the results in these more controlled studies: ${ }^{\text {in fact, it has }}$ already been shown that the positive PDT results for planktonic culture were not repeated with the biofilm formed "in situ" using the same dosimetry. ${ }^{13}$

The variety of protocols for applying laser or LED light and the existence of few studies that assess the properties of the available dyes and light sources hinder the comparison of the findings on PDT. ${ }^{24}$

We have found only one clinical study on PDT in the carious dentin of permanent teeth, in which a significant reduction in the counts of total microorganisms, mutans streptococci and Lactobacillus spp. was observed. ${ }^{14}$ It may be that the dentinal substrate contributed to the differences between the findings of the study carried out with permanent teeth ${ }^{14}$ and this study, which used caries lesions on deciduous teeth. However, it should be stressed that the difference in substrates may have been minimized, as that PDT was applied to caries lesions in the deep dentin in both studies.

The difference in applied dosimetry might be another explanation for why we did not observe PDT 
effects in the present study, where the dosimetry used was $120 \mathrm{~J} / \mathrm{cm}^{2}$ and, therefore, lower than in the clinical study that obtained positive effects in permanent teeth, which used $320 \mathrm{~J} / \mathrm{cm}^{2} .{ }^{14} \mathrm{In}$ an additional experiment using $180 \mathrm{~J} / \mathrm{cm}^{2}$ in the remaining dentin of 10 primary molars, extending the time of laser application for $180 \mathrm{~s}$ and using the maximum power output of the device to red light $(40 \mathrm{~mW})$; still found no significant antimicrobial effect (data not shown). This last dosimetry is the maximum limit for the red laser of our device.

In this study, PDT caused an average log reduction of 0.46 for mutans streptococci, 0.44 for Lactobacillus spp. and 0.61 for total microorganisms; however, this reduction was not significant compared to the controls before treatment. In the study on carious dentin of permanent teeth, the log reduction was approximately 1.38 for mutans streptococci, 0.93 for Lactobacillus spp. and 0.91 for total microorganisms, all of which were statistically significant. ${ }^{14}$ Thus, although an effect of PDF was observed in that clinical study with permanent teeth, its effect was low to be considered dose-effective because it should induce a reduction of at least $2-\log \mathrm{CFU} .^{25}$

The limited penetration of the dye in the carious dentin may be another explanation for the lack of PDT effect observed in this study. It has been shown that the penetration of toluidine blue and methylene blue in healthy dentin are, respectively, 130 and $190 \mu \mathrm{m},{ }^{26}$ and this penetration is even smaller in the carious dentin, only $52.6 \mu \mathrm{m}$ below the surface. ${ }^{27}$ Therefore, the altered structure of the carious dentin may not allow adequate penetration of the photosensitizer ${ }^{28,14}$ and its interaction with microorganisms such as the ones in the mutans group, which have been observed in dental tubules at depths of $200 \mu \mathrm{m}$ or more from the dentinal surface. ${ }^{29}$ The study of new parameters such as the type and concentration of the dyes may give new perspectives for an antimicrobial effect of PDT.

In this sense, Longo et al. ${ }^{30}$ using a different photosensitizer (aluminum-chloride-phthalocyanine - AlClPc entrapped in cationic liposomes) using a dosimetry of $180 \mathrm{~J} / \mathrm{cm}^{2}$ in carious dentin of primary/permanent molars $(n=12)$, found a significant reduction in absolutes values of CFU
(82\%), however no percentual CFU reduction was observed after PDT application ( $p=0.15)$. It would be possible that the photosensitizer used (AlClPc entrapped in cationic liposomes) could be more promising than Methylene blue here used to bacterial reduction in carious dentin. However that study showed no statistic difference in percentual CFU reduction and also it was not presented an CFU-log reduction, which would impose a clinical relevance to their results. ${ }^{25}$

However it is important to consider that residual contamination of the deep dentin, after cavity preparation, is still a cause of concern among investigators, as certain strains seem to adapt to the new environment that is created under restorations. ${ }^{4}$ Viable bacteria were found even after total removal of the carious tissue, immediately after preparation, or re-contaminating the cavity some months after restorations were in place. ${ }^{3}$ Therefore, even if one attempts to "sterilize" the residual bacterial contamination after cavity preparation, there seem to be other factors that can lead to the presence of bacteria on the tooth-restoration interface after a period of clinical intervention in the oral cavity that are not dependent on the conditions left immediately after preparation. ${ }^{3}$ Conversely, after partial removal of carious dentin, there is a drastic reduction in microbiota complexity, or even an absence of bacteria after a period of cavity sealing by restoration material., ${ }^{2,3}$

\section{Conclusion}

Our results indicate that PDT using $0.01 \%$ methylene blue dye at a dosimetry of 120 to $180 \mathrm{~J} / \mathrm{cm}^{2}$ would not be a viable clinical alternative to reduce bacterial contamination in deep dentin. Other studies may be conducted testing new photosensitizers or dosages to establish an effective protocol to PDT reduction in caries tissue with clinical relevance.

\section{Acknowledgments}

This research was financially supported by FAPEMA (Fundação de Amparo à Pesquisa e ao Desenvolvimento Científico e Tecnológico do Maranhão - Portuguese acronym for the MaranhãoState Research Foundantion), grant APP-UNIVERSAL-00400/11. 


\section{References}

1. Fusayama T, Okuse K, Hosoda H. Relationship between hardness, discoloration, and microbial invasion in carious dentin. J Dent Res. 1966;45(4):1033-46. doi:10.1177/00220345660450040401

2. Paddick JS, Brailsford SR, Kidd EA, Beighton D. Phenotypic and genotypic selection of microbiota surviving under dental restorations. Appl Environ Microbiol. 2005;71(5):2467-72. doi:10.1128/AEM.71.5.2467-2472.2005

3. Lula EC, Monteiro-Neto V, Alves CM, Ribeiro CC. Microbiological analysis after complete or partial removal of carious dentin primary teeth: a randomized clinical trial. Caries Res. 2009;43(5):354-8. doi:10.1159/000231572

4. Duque C, Negrini TC, Sacono NT, Boriollo MFG, Höfling JF, Hebling J, et al. Genetic polymorphism of Streptococcus mutans strains associated with incomplete caries removal. Braz J Oral Sci. 2009;8(1):2-8.

5. Williams JA, Pearson GJ, Colles MJ, Wilson M. The photo-activated antibacterial action of toluidine blue $\mathrm{O}$ in a collagen matrix and in carious dentine. Caries Res. 2004;38(6):530-6. doi:10.1159/000080582

6. Santin GC, Oliveira DSB, Galo R, Borsatto MC, Corona SAM. Antimicrobial photodynamic therapy and dental plaque: a systematic review of the literature. ScientificWorldJournal. 2014;2014:824538. doi:10.1155/2014/824538

7. Paschoal MAB, Duarte S, Santos-Pinto LAM. Photodynamic antimicrobial chemotherapy for prevention and treatment of dental caries: a critical review. OA Dentistry. 2013;1(1):1-5. doi:10.13172/2054-2526-1-1-946

8. Hakimiha N, Khoei F, Bahador A, Fekrazad R. The susceptibility of Streptococcus mutans to antibacterial photodynamic therapy: a comparison of two different photosensitizers and light sources. J Appl Oral Sci. 2014;22(2):80-4. doi:10.1590/1678-775720130038

9. Pereira CA, Costa AC, Carreira CM, Junqueira JC, Jorge AO. Photodynamic inactivation of Streptococcus mutans and Streptococcus sanguinis biofilms in vitro. Lasers Med Sci. 2013;28(3):859-64. doi:10.1007/s10103-012-1175-3

10. O'Neill JF, Hope CK, Wilson M. Oral bacteria in multispecies biofilms can be killed by red light in the presence of toluidine blue. Lasers Surg Med. 2002;31(2):86-90. doi:10.1002/1sm.10087

11. Giusti JS, Santos-Pinto L, Pizzolito AC, Helmerson K, Carvalho-Filho E, Kurachi C, et al. Antimicrobial photodynamic action on dentin using a light-emitting diode light source. Photomed Laser Surg. 2008;26(4):281-7. doi:10.1089/pho.2007.2149

12. Lima JPM, Melo MAS, Borges FMC, Teixeira AH, Steiner-Oliveira C, Santos MN, et al. Evaluation of the antimicrobial effect of photodynamic antimicrobial therapy in an in situ model of dentine caries. Eur J Oral Sci. 2009;117(5):568-74. doi: 10.1111/j.1600-0722.2009.00662.x
13. Teixeira AH, Pereira ES, Rodrigues LK, Saxena D, Duarte S, Zanin IC. Effect of photodynamic antimicrobial chemotherapy on in vitro and in situ biofilms. Caries Res. 2012;46(6):549-54. doi: 10.1159/000341190

14. Guglielmi CA, Simionato MR, Ramalho KM, Imparato JC, Pinheiro SL, Luz MA. Clinical use of photodynamic antimicrobial chemotherapy for the treatment of deep carious lesions. J Biomed Opt. 2011;16(8):088003. doi:10.1117/1.3611009

15. Ekstrand KR, Martignon S, Ricketts DJ, Qvist V. Detection and activity assessment of primary coronal caries lesions: a methodologic study. Oper Dent. 2007;32(3):225-35. doi:10.2341/06-63

16. Kidd EAM, Joyston-Bechal S, Beighton D. Microbiological validation of assessments of caries activity during cavity preparation. Caries Res. 1993;27(5):402-8. doi:10.1159/000261571

17. Müller P, Guggenheim B, Schmidlin PR. Efficacy of gasiform ozone and photodynamic therapy on a multispecies oral biofilm in vitro. Eur J Oral Sci. 2007;115(1):77-80. doi:10.1111/j.1600-0722.2007.00418.x

18. Gold OG, Jordan HV, Van Houte J. A selective medium for Streptococcus mutans. Arch Oral Biol. 1973;18(11):1357-64. doi:10.1016/0003-9969(73)90109-X

19. Rogosa M, Mitchell JA, Wiseman RF. A selective medium for the isolation and enumeration of oral lactobacilli. J Dent Res. 1951;30(5):682-9. doi:10.1177/00220345510300051201

20. Ersin NK, Eronat N, Cogulu D, Uzel A, Aksit S. Association of maternal-child characteristics as a factor in early childhood caries and salivary bacterial counts. J Dent Child (Chic). 2006;73(2):105-11.

21. Paschoal MAB, Lin M, Santos-Pinto L, Duarte S. Photodynamic antimicrobial chemotherapy on Streptococcus mutans using curcumin and toluidine blue activated by a novel LED device. Lasers Med Sci. 2015;30(2):885-90. doi:10.1007/s10103-013-1492-1

22. Marsh PD. Dental plaque as a microbial biofilm. Caries Res. 2004;38(3):204-11. doi:10.1159/000077756

23. Marsh PD. The role of microbiology in models of dental caries. Adv Dent Res. 1995;9(3):244-54.

24. Nagata JY, Hioka N, Kimura E, Batistela VR, Terada RS, Graciano AC, et al. Antibacterial photodynamic therapy for dental caries: evaluation of the photosensitizers used and light source properties. Photodiagn Photodyn Ther. 2012;9(2):122-31. doi:10.1016/j.pdpdt.2011.11.006

25. Concannon SP, Crowe TD, Abercrombie JJ, Molina CM, Hou P, Sukumaran DK, et al. Susceptibility of oral bacteria to an antimicrobial decapeptide. J Med Microbiol. 2003;52(12):1083-93. doi:10.1099/jmm.0.05286-0

26. Nogueira AC, Graciano AX, Nagata JY, Fujimaki M, Terada RS, Bento AC, et al. Photosensitizer and light diffusion through dentin in photodynamic 
- Clinical effect of photodynamic therapy on primary carious dentin after partial caries removal

therapy. J Biomed Opt. 2013;18(5):055004.

doi:10.1117/1.JBO.18.5.055004

27. Melo MAS, Rolim JPML, Zanin ICJ, Silva JJA, Paschoal AR, Ayala AP, et al. A comparative study of photosensitizer penetration into artificial caries lesion in dentin measured by the confocal Raman microscopy. Photochem Photobiol. 2013;90(1):183-8. doi:10.1111/php.12186

28. Kouchi, Y, Ninomiya J, Yasuda H, Fukui K, Moriyama $\mathrm{T}$, Okamoto H. Location of Streptococcus mutans in the dentinal tubules of open infected root canals. J Dent Res. 1980;59(12):2038-46. doi:10.1177/00220345800590120301
29. Love RM, McMillan MD, Jenkinson HF. Invasion of dentinal tubules by oral streptococci is associated with collagen recognition mediated by the antigen I/II family of polypeptides. Infect Immun. 1997;65(12):5157-64.

30. Longo JPF, Leal SC, Simione AR, Almeida-Santos MFM, Tedesco AC, Azevedo RB. Photodynamic therapy disinfection of carious tissue mediated by aluminum-chloride-phthalocyanine entrapped in cationic liposomes: an in vitro and clinical study. Lasers Med Sci. 2012;27(3):575-84. doi:10.1007/s10103-011-0962-6 